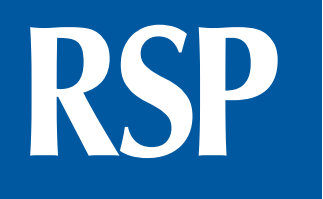

http://www.rsp.fsp.usp.br/
Revista de Saúde Pública

\title{
Factors associated with low adherence to medicine treatment for chronic diseases in Brazil
}

Noemia Urruth Leão Tavares ', Andréa Dâmaso Bertoldi ", Sotero Serrate Mengue "', Paulo Sergio Dourado Arrais iv , Vera Lucia Luiza ${ }^{\mathrm{v}}$, Maria Auxiliadora Oliveira ${ }^{\mathrm{v}}$, Luiz Roberto Ramos ${ }^{\mathrm{V}}$, Mareni Rocha Farias VII, Tatiane da Silva Dal Pizzol VIII

' Departamento de Farmácia. Faculdade de Ciências da Saúde. Universidade de Brasília. Brasília, DF, Brasil

" Departamento de Medicina Social. Faculdade de Medicina. Universidade Federal de Pelotas. Pelotas, RS, Brasil

II' Programa de Pós-Graduação em Epidemiologia. Universidade Federal do Rio Grande do Sul. Porto Alegre, RS, Brasil

iv Departamento de Farmácia. Faculdade de Farmácia, Odontologia e Enfermagem. Universidade Federal do Ceará. Fortaleza, CE, Brasil

$\checkmark$ Departamento de Política de Medicamentos e Assistência Farmacêutica. Escola Nacional de Saúde Pública Sérgio Arouca. Fundação Oswaldo Cruz. Rio de Janeiro, RJ, Brasil

vı Departamento de Medicina Preventiva. Escola Paulista de Medicina. Universidade Federal de São Paulo. São Paulo, SP, Brasil

VII Departamento de Ciências Farmacêuticas, Centro de Ciências da Saúde. Universidade Federal de Santa Catarina. Florianópolis, SC, Brasil

VIII Departamento de Produção e Controle de Medicamentos. Faculdade de Farmácia. Universidade Federal do Rio Grande do Sul. Porto Alegre, RS, Brasil

\section{ABSTRACT}

OBJECTIVE: To analyze factors associated with low adherence to drug treatment for chronic diseases in Brazil.

METHODS: Analysis of data from Pesquisa Nacional sobre Acesso, Utilização e Promoção do Uso Racional de Medicamentos (PNAUM - Brazilian Survey on Access, Use and Promotion of Rational Use of Medicines), a population-based cross-sectional household survey, based on a probabilistic sample of the Brazilian population. We analyzed the association between low adherence to drug treatment measured by the Brief Medication Questionnaire and demographic, socioeconomic, health, care and prescription factors. We used Poisson regression model to estimate crude and adjusted prevalence ratios, their respective $95 \%$ confidence interval (95\%CI) and p-value (Wald test).

RESULTS: The prevalence of low adherence to drug treatment for chronic diseases was $30.8 \%$ (95\%CI 28.8-33.0). The highest prevalence of low adherence was associated with individuals: young adults; no education; resident in the Northeast and Midwest Regions of Brazil; paying part of the treatment; poor self-perceived health; three or more diseases; reported limitations caused by a chronic disease; using five drugs or more.

How to cite: Tavares NUL, Bertoldi AD, Mengue SS, Arrais PSD, Luiza VL, Oliveira MA, et al. Factors Associated with low adherence to drug treatment for chronic diseases in Brazil. Rev Saude Publica. 2016;50(suppl 2):10s.

Copyright: This is an open-access article distributed under the terms of the Creative Commons Attribution License, which permits unrestricted use, distribution, and reproduction in any medium, provided that the original author and source are credited.

CONCLUSIONS: Low adherence to drug treatment for chronic diseases in Brazil is relevant, and regional and demographic differences and those related to patients' health care and therapy regime require coordinated action between health professionals, researchers, managers and policy makers.

DESCRIPTORS: Patient Dropouts. Medication Adherence. Drugs of Continuous Use. Chronic Disease. Health Services Accessibility. Socioeconomic Factors. Health Surveys. 


\section{INTRODUCTION}

Noncommunicable diseases, a global health problem, are the target of various prevention and control programs and initiatives ${ }^{1}$. Many noncommunicable diseases can be controlled by the use of drugs, which, when available and properly used, lead to therapeutic success. An important factor that directly influences therapeutic outcomes is adherence to drug treatment, defined as the degree of agreement between a person's behavior and professional guidance ${ }^{22}$.

Factors related to non-adherence to treatment described in the literature concern individual characteristics of patients, the actual disease, the drugs used and interaction between patients and health services, among others ${ }^{20}$. The characteristics of certain health conditions or therapies may lead to specific barriers to adherence. For some asymptomatic diseases such as high blood pressure, patients may have difficulty to use drugs regularly because of the lack of visible symptoms or understanding of the disease's behavior ${ }^{15}$. For illnesses that require complex regimes (polypharmacy, multiple daily administrations, difficulties with administration), such as asthma and diabetes, the actual daily difficulties associated with the use of drugs are an important barrier to adherence ${ }^{3}$.

According to the World Health Organization (WHO), non-adherence to long-term treatment in the population at large is around $50.0 \%^{20}$. In a systematic review summarizing studies published over 50 years, DiMatteo ${ }^{5}$ (2004) identified an average non-adherence rate of $24.8 \%$.

Brazil lacks sufficient evidence on the prevalence of low adherence among patients with chronic diseases based on nationwide studies. The available studies used local or regional samples $^{17}$, population subgroups (such as older adults) ${ }^{20}$, or focused on specific chronic diseases such as high blood pressure ${ }^{6,718}$. Therefore, studies that estimate treatment adherence among the Brazilian population with chronic diseases are important to support health policy and practice aimed at improving access to and rational use of drugs.

The aim of this study was to analyze factors associated with low adherence to drug treatment for chronic diseases in Brazil.

\section{METHODS}

The data analyzed in this study are from Pesquisa Nacional sobre Acesso, Utilização e Promoção do Uso Racional de Medicamentos (PNAUM - National Survey on Access, Use and Promotion of Rational Use of Medicines), a population-based cross-sectional household survey, based on a probabilistic sample of the Brazilian population. Data were collected from September 2013 to February 2014. The study population lived in permanent private households in urban areas of Brazil, and included individuals of all ages. Face-to-face interviews were carried out in households using questionnaires, and data were collected and stored in electronic devices. The tools were developed by a group of expert researchers from Brazilian universities and standardized and tested before being administered.

The complex sampling process resulted in a sample that ensured national representation for the five Brazilian regions, stratified by gender and age groups. Further details on sampling and data collection can be found in the PNAUM methodology article ${ }^{13}$. This study included adults aged 20 or older who reported at least one chronic disease diagnosed at least six months prior to the interview $(\mathrm{n}=14,358)$. The investigation on adherence to drug treatment included all subjects who reported medical indication for treatment and were using medication for the chronic diseases mentioned at the interview $(n=11,842)$.

To assess adherence reported by patients, we used the Brief Medication Questionnaire (BMQ), composed of three areas that identify barriers to adherence related to the regime, beliefs, and memories of the drug treatment. We used the $\mathrm{BMQ}^{2}$ version translated into Portuguese, which classifies individuals into four categories of adherence to treatment, 
according to the number of positive responses in any of the areas: high adherence (none), likely high adherence (1), likely low adherence (2), and low adherence (3 or more). The outcome analyzed in this study was prevalence of low adherence to treatment, considered as a score of 2 or more in any field.

The variables related to demographic and socioeconomic characteristics were: gender (female; male); age group (20-39; 40-59; 60 and over); self-reported skin color (white, non-white), marital status (with partner; without partner); education reported in grades and reclassified in years of study (0, 1-8, 8 years or more); economic status according to Critério de Classificação Econômica Brazil (Brazilian Economic Classification Criterion) of Associação Brasileira de Empresas de Pesquisa (ABEP - Brazilian Association of Survey Companies [A/B; $\mathrm{C} ; \mathrm{D} / \mathrm{E}]$ ), geographic region of residence (North, Northeast, Southeast, South, Midwest) and whether the respondent had health insurance.

Regarding health care, we analyzed the number of hospitalizations and emergency visits in the previous year (none, one, two or more), if the individual visits and has a single doctor to treat the diseases, and free access to medicines (all drugs; any drug; no drugs).

Regarding perception of health and morbidities, the following variables were evaluated: number of chronic diseases reported (high blood pressure; diabetes; stroke; lung disease; depression; rheumatism; other chronic diseases lasting more than six months) grouped into one, two, three or more conditions; self-perceived health, analyzed in five categories (very poor; poor; average; good; very good); and reported limitations related to at least one chronic disease. Regarding drug use, we analyzed the number of drugs used (continuous or occasional) (1; $2 ; 3$ or $4 ; 5$ or more).

The analyses were performed with Stata version 11.0 software, using the appropriate set of svy commands to analyze complex samples and ensuring the necessary weighting, considering the sample design. Exploratory descriptive analysis was performed for all the variables involved in the study, presenting the relative frequencies and respective 95\% confidence intervals $(95 \% \mathrm{CI})$. For the univariate analysis, the BMQ score was dichotomized, considering as low adherence a score of two or more. In the crude analysis, the prevalence of low adherence to treatment was calculated for the categories of the independent variables, considering the dichotomous outcome. A 5\% significance level was adopted.

We used Poisson regression model to estimate crude and adjusted prevalence ratios (PR) and $95 \%$ CI, considering the effect of the sample design with Stata svy commands. We attempted to control possible confounding factors in the multivariate analysis, using a hierarchical analysis model (Figure). Variables with $\mathrm{p}<0.20$ were included in the multivariate model, and we adopted a significance level of $5 \%$ to retain variables in the model, with "backward" selection of variables. The statistical significance of prevalence ratios obtained in Poisson regression models was assessed by the Wald test.

The study was approved by the Comissão Nacional de Ética em Pesquisa (National Research Ethics Committee - Opinion 398,131, of September 6, 2013). All interviews were conducted after the respondents or their legal representatives had read and signed the consent form.

\section{RESULTS}

Table 1 shows the adherence classification according to BMQ. The prevalence of low adherence (dichotomized score) to drug treatment for chronic diseases in Brazil was 30.8\% (95\%CI 28.8-33.0) and only 2.6\% (95\%CI 2.1-3.2) of respondents were classified as adhering to prescribed therapies (no positive response in the evaluated areas).

The sample breakdown and prevalence of low adherence in relation to socioeconomic and demographic characteristics are shown in Table 2. Prevalence of low adherence (statistically significant) was higher in the following categories: younger individuals (20-39 years) and 
those residing in the Northeast and Midwest Regions. Prevalence of low adherence was also higher, although not statistically significant, among individuals who were female, non-white, reported not having a partner and having no education, D/E economic status, and without health insurance.

The characteristics of individuals with low adherence to treatment related to health care, self-perception and morbidities, and the use of drugs, are presented in Table 3. Prevalence of low adherence was higher in those individuals who do not see a doctor to treat chronic diseases, although it was not statistically significant. On the other hand, individuals visiting more than one doctor to treat those diseases had a $47.0 \%$ higher likelihood of low adherence to treatment than those who had only one doctor. Those who had to pay part of the treatment, had two or more hospitalizations, or received emergency care in the previous year had an $80.0 \%$ lower adherence to treatment, approximately.

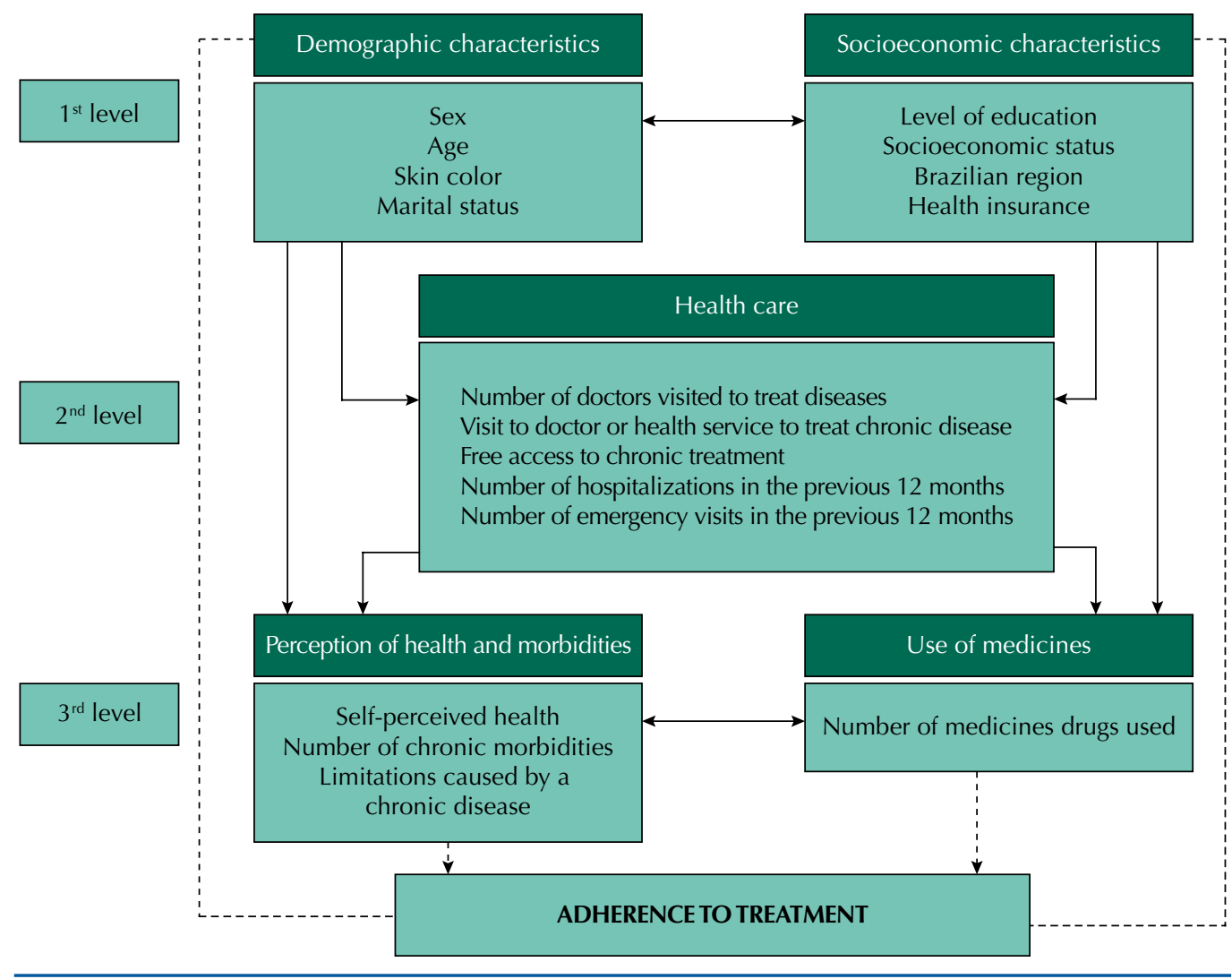

Figure 1. Hierarchical model for the analysis of factors associated to adherence to drug therapy for chronic diseases in Brazil. PNAUM, Brazil, 2014.

Table 1. Classification of adherence to treatment for chronic diseases by adults aged 20 or over in Brazila. PNAUM, Brazil, 2014. ( $\mathrm{N}=11,842)$

\begin{tabular}{|c|c|c|}
\hline $\mathrm{BMQ}^{\mathrm{a}}$ & $\%^{b}$ & $95 \% \mathrm{Cl}$ \\
\hline \multicolumn{3}{|l|}{ Categorical score } \\
\hline Adherence & 2.6 & $2.1-3.2$ \\
\hline Likely adherence & 66.6 & $64.4-68.7$ \\
\hline Likely low adherence & 17.0 & $15.5-18.6$ \\
\hline Low adherence & 13.8 & $12.7-15.1$ \\
\hline \multicolumn{3}{|l|}{ Dichotomous BMQ score } \\
\hline Adherence or likely adherence & 69.2 & $67.0-71.2$ \\
\hline Likely low adherence or low adherence & 30.8 & $28.8-33.0$ \\
\hline
\end{tabular}

according to Brief Medication Questionnaire (BMQ).

${ }^{\mathrm{b}}$ Percentage adjusted by sample weighting and post-stratification by age and gender. 
Table 2. Prevalence of low adherence ${ }^{a, b}$ to treatment for chronic diseases by adults aged 20 or over in Brazil, by demographic and socioeconomic characteristics. PNAUM, Brazil, 2014. $(\mathrm{N}=11,842)$

\begin{tabular}{|c|c|c|c|c|}
\hline \multirow{2}{*}{ Variable } & \multicolumn{2}{|c|}{ Breakdown in sample } & \multicolumn{2}{|c|}{ Prevalence of low adherence ${ }^{c}$} \\
\hline & $\%^{\mathrm{a}}$ & $95 \%$ IC & $\%^{a}$ & $95 \%$ IC \\
\hline \multicolumn{5}{|c|}{ Demographic characteristics } \\
\hline \multicolumn{5}{|l|}{ Gender } \\
\hline Male & 35.3 & $33.9-36.7$ & 28.3 & $25.4-31.5$ \\
\hline Female & 64.7 & $63.3-66.1$ & 32.1 & $29.9-34.4$ \\
\hline \multicolumn{5}{|l|}{ Age (years) } \\
\hline $20-39$ & 15.0 & $13.6-16.6$ & 38.6 & $33.1-44.5$ \\
\hline $40-59$ & 42.8 & $41.1-44.4$ & 30.3 & $27.8-33.0$ \\
\hline$\geq 60$ & 42.2 & $40.4-44.0$ & 28.7 & $26.5-31.0$ \\
\hline \multicolumn{5}{|l|}{ Skin color } \\
\hline White & 50.6 & $47.8-53.4$ & 30.0 & $27.3-32.8$ \\
\hline Non-white & 49.4 & $46.6-52.2$ & 31.4 & $28.9-34.0$ \\
\hline \multicolumn{5}{|l|}{ Marital status } \\
\hline With partner & 61.4 & $59.8-62.9$ & 30.5 & $28.3-32.8$ \\
\hline Without partner & 38.6 & $37.1-40.2$ & 31.6 & $28.9-34.5$ \\
\hline \multicolumn{5}{|c|}{ Socioeconomic characteristics } \\
\hline \multicolumn{5}{|c|}{ Level of education (years of study) } \\
\hline No education & 15.0 & $13.7-16.4$ & 35.5 & $31.5-39.8$ \\
\hline 1 to 8 years & 43.1 & $41.2-45.0$ & 28.5 & $25.8-31.3$ \\
\hline$\geq 8$ years & 41.8 & $40.0-43.7$ & 31.7 & $29.3-34.2$ \\
\hline \multicolumn{5}{|c|}{ Economic status ABEPd } \\
\hline $\mathrm{A} / \mathrm{B}$ & 24.6 & $22.3-27.0$ & 30.6 & $26.9-34.6$ \\
\hline $\mathrm{C}$ & 54.8 & $52.9-56.7$ & 30.3 & $28.0-32.7$ \\
\hline $\mathrm{D} / \mathrm{E}$ & 20.7 & $18.9-22.5$ & 32.6 & $29.2-36.2$ \\
\hline \multicolumn{5}{|l|}{ Brazilian region } \\
\hline North & 4.2 & $3.2-5.3$ & 22.7 & $18.8-27.1$ \\
\hline Northeast & 20.6 & $16.8-25.0$ & 38.1 & $35.1-41.2$ \\
\hline Southeast & 51.9 & $46.0-57.8$ & 29.2 & $25.7-33.0$ \\
\hline South & 15.7 & $12.7-19.3$ & 26.8 & $24.5-29.2$ \\
\hline Midwest & 7.7 & $6.0-9.8$ & 35.5 & $31.6-39.6$ \\
\hline \multicolumn{5}{|l|}{ Health plan } \\
\hline Yes & 28.4 & $26.0-31.0$ & 29.0 & $26.1-32.1$ \\
\hline No & 71.6 & $69.0-74.0$ & 31.6 & $29.3-34.0$ \\
\hline Total & & & 30.8 & $28.8-33.0$ \\
\hline
\end{tabular}

a According to Brief Medication Questionnaire (BMQ).

${ }^{\mathrm{b}}$ Percentage adjusted by sample weighting and post-stratification by age and gender.

c Non-adherence $=$ low adherence according to BMQ (2 or more positive answers).

${ }^{\mathrm{d}}$ According to Critério de Classificação Econômica Brasil 2013 - ABEP (www.abep.org).

Self-perceived health was strongly associated with low adherence to treatment, i.e., the likelihood of low adherence was about three times higher in those with poor or very poor self-perceived health. Regarding the number of chronic diseases, among those with three or more, prevalence of low adherence was about double that of individuals with only one disease. Those who reported limitations caused by chronic diseases had about $80.0 \%$ lower adherence to treatment.

Regarding the therapy regimen used to treat reported chronic diseases, those who were taking five or more drugs had 2.4 times lower adherence to treatment than those who used only one drug.

Table 4 features the results of the crude and adjusted analyses. In the crude analysis, the variables skin color, marital status, economic status and seeing a doctor to treat chronic diseases were not statistically significant and therefore did not enter the adjusted analysis model. After adjustment for potential confounders in the multivariate analysis, the 
variables gender, level of education, number of hospitalizations in the last 12 months and self-perceived health lost their statistical significance. The following remained associated with low adherence to treatment for chronic diseases after the adjusted analysis: age, region, health insurance, number of doctors seen to treat chronic diseases, free access to therapy, number of emergency visits in the last 12 months, number of chronic diseases, limitation caused by disease and use of medicines.

Table 3. Prevalence of low adherence ${ }^{a, b}$ to treatment for chronic diseases by adults aged 20 or over in Brazil, by characteristics related to health care, health perception, morbidities and drug use. PNAUM, Brazil, 2014. $(\mathrm{N}=11,842)$

\begin{tabular}{|c|c|c|c|c|}
\hline \multirow{2}{*}{ Variable } & \multicolumn{2}{|c|}{ Sample breakdown } & \multicolumn{2}{|c|}{ Prevalence of low adherence } \\
\hline & $\%$ & $95 \%$ IC & $\%$ & $95 \%$ IC \\
\hline \multicolumn{5}{|c|}{ Health system characteristics } \\
\hline \multicolumn{5}{|c|}{ Visits doctor to treat chronic diseases } \\
\hline Yes & 93.3 & $92.3-94.2$ & 31.2 & $29.0-33.5$ \\
\hline No & 6.7 & $5.8-7.7$ & 32.3 & $27.9-37.0$ \\
\hline \multicolumn{5}{|c|}{ Number of doctors visited to treat chronic diseases } \\
\hline One & 68.2 & $66.3-70.0$ & 27.2 & $24.9-29.6$ \\
\hline More than one & 31.8 & $30.0-33.7$ & 40.1 & $37.2-43.2$ \\
\hline \multicolumn{5}{|c|}{ Free access to chronic drug therapy for chronic diseases } \\
\hline All free & 46.9 & $44.5-49.2$ & 25.4 & $23.0-28.1$ \\
\hline Any free & 20.3 & $19.1-21.5$ & 46.6 & $42.7-50.7$ \\
\hline None free & 32.9 & $30.8-35.1$ & 29.0 & $26.5-31.7$ \\
\hline \multicolumn{5}{|c|}{ Number of hospitalizations in the previous 12 months } \\
\hline None & 89.1 & $88.2-90.0$ & 29.8 & $27.7-32.1$ \\
\hline 1 & 8.2 & $7.5-9.0$ & 34.6 & $29.8-39.8$ \\
\hline 2 or more & 2.7 & $2.2-3.2$ & 51.8 & $42.7-60.9$ \\
\hline \multicolumn{5}{|c|}{ Number of emergency visits in the previous 12 months } \\
\hline None & 77.0 & $75.3-78.6$ & 27.1 & $25.0-29.3$ \\
\hline 1 & 14.9 & 13.8-16.0 & 39.8 & $36.2-43.7$ \\
\hline 2 or more & 8.1 & $7.2-9.1$ & 50.0 & $44.6-55.4$ \\
\hline \multicolumn{5}{|c|}{ Self-perceived health and morbidities } \\
\hline \multicolumn{5}{|c|}{ Self-perceived health } \\
\hline Very good & 5.1 & $4.4-5.9$ & 17.2 & $11.4-25.1$ \\
\hline Good & 45.6 & $43.6-47.6$ & 25.0 & $22.6-27.7$ \\
\hline Average & 40.8 & $39.1-42.4$ & 35.9 & $33.4-38.5$ \\
\hline Poor & 6.3 & $5.6-7.0$ & 46.4 & $41.1-51.7$ \\
\hline Very poor & 2.3 & $1.9-2.7$ & 49.6 & $39.7-59.5$ \\
\hline \multicolumn{5}{|c|}{ Number of chronic diseases (comorbidities) } \\
\hline 1 & 44.8 & $42.9-46.7$ & 20.9 & $18.8-23.1$ \\
\hline 2 & 27.2 & $26.1-28.4$ & 33.3 & $30.6-36.1$ \\
\hline 3 or more & 28.0 & $26.3-29.7$ & 44.2 & $41.0-47.4$ \\
\hline \multicolumn{5}{|c|}{ Limitations due to chronic disease } \\
\hline No limitations & 48.5 & $46.7-50.3$ & 21.9 & 19.9-24.1 \\
\hline Limitations & 51.5 & $49.7-53.3$ & 39.5 & $36.9-42.2$ \\
\hline \multicolumn{5}{|l|}{ Use of drugs } \\
\hline \multicolumn{5}{|c|}{ Number of drugs used (continuous or occasional) } \\
\hline 1 & 34.6 & $33.2-36.0$ & 20.6 & $18.2-23.2$ \\
\hline 2 & 26.0 & $24.7-27.3$ & 26.4 & $23.8-29.2$ \\
\hline 3 to 4 & 26.0 & $24.8-27.3$ & 38.9 & $35.6-42.4$ \\
\hline 5 or more & 13.4 & $12.5-14.4$ & 50.1 & 46.4-53.8 \\
\hline Total & & & 30.8 & 28.8-33.0 \\
\hline
\end{tabular}

a Percentage adjusted by sample weighting and post-stratification by age and gender.

${ }^{\mathrm{b}}$ Non-adherence $=$ low adherence according to the Brief Medication Questionnaire BMQ (2 or more positive answers). 
Table 4. Crude and adjusted ${ }^{\mathrm{a}, \mathrm{b}}$ prevalence ratios of low adherence to treatment for chronic diseases by adults aged 20 or over in Brazil, by analyzed variables. PNAUM, Brazil, 2014. ( $N=11,842)$

\begin{tabular}{|c|c|c|c|c|c|c|}
\hline \multirow{2}{*}{ Variable $^{c}$} & \multicolumn{3}{|c|}{ Crude analysis } & \multicolumn{3}{|c|}{ Adjusted analysis } \\
\hline & PR & $95 \%$ IC & $p^{d}$ & PR & $95 \%$ IC & $\mathbf{P}^{\mathbf{d}}$ \\
\hline \multicolumn{7}{|c|}{ Level 1} \\
\hline \multicolumn{7}{|l|}{ Demographic characteristics } \\
\hline Gender & & & 0.017 & & & \\
\hline Male & Ref & & & & & \\
\hline Female & 1.13 & $1.02-1.25$ & & & & \\
\hline Age (years) & & & $<0.001$ & & & $<0.001$ \\
\hline $20-39$ & 1.34 & $1.16-1.56$ & & 1.64 & $1.39-1.93$ & \\
\hline $40-59$ & 1.05 & $0.95-1.16$ & & 1.16 & $1.04-1.29$ & \\
\hline$\geq 60$ & Ref & & & & & \\
\hline Skin color & & & 0.383 & & & \\
\hline White & Ref & & & & & \\
\hline Non-white & 1.04 & $0.94-1.16$ & & & & \\
\hline Marital status & & & 0.409 & & & \\
\hline With partner & Ref & & & & & \\
\hline Without partner & 1.03 & $0.95-1.12$ & & & & \\
\hline \multicolumn{7}{|l|}{ Socioeconomic characteristics } \\
\hline Level of education (years of study) & & & 0.003 & & & \\
\hline No education & 1.11 & $0.97-1.27$ & & & & \\
\hline 1 to 8 years & 0.89 & $0.81-0.99$ & & & & \\
\hline$\geq 8$ years & Ref & & & & & \\
\hline Economic status ABEPd & & & 0.372 & & & \\
\hline $\mathrm{A} / \mathrm{B}$ & Ref & & & & & \\
\hline $\mathrm{C}$ & 0.98 & $0.86-1.12$ & & & & \\
\hline $\mathrm{D} / \mathrm{E}$ & 1.06 & $0.90-1.25$ & & & & \\
\hline Brazilian region & & & $<0.001$ & & & $<0.001$ \\
\hline North & Ref & & & & & \\
\hline Northeast & 1.68 & $1.37-2.05$ & & 1.33 & $1.10-1.61$ & \\
\hline Southeast & 1.28 & $1.03-1.61$ & & 1.11 & $0.90-1.38$ & \\
\hline South & 1.18 & $0.96-1.44$ & & 0.98 & $0.81-1.18$ & \\
\hline Midwest & 1.56 & $1.26-1.94$ & & 1.21 & $1.00-1.47$ & \\
\hline Health plan & & & 0.102 & & & 0.031 \\
\hline Yes & 0.91 & $0.82-1.01$ & & 0.89 & $0.81-0.99$ & \\
\hline No & Ref & & & & & \\
\hline \multirow{2}{*}{\multicolumn{7}{|c|}{ Health system characteristics }} \\
\hline & & & & & & \\
\hline \multicolumn{3}{|c|}{ Visits doctor to treat chronic diseases } & 0,668 & & & \\
\hline Yes & Ref & & & & & \\
\hline No & 0.96 & $0.82-1.12$ & & & & \\
\hline Number of doctors visited to trea & hronic c & & $<0.001$ & & & $<0.001$ \\
\hline One & Ref & & & & & \\
\hline More than one & 1.47 & $1.34-1.61$ & & 1.16 & $1.06-1.26$ & \\
\hline Free access to drug therapy for $\mathrm{cl}$ & nic dise & & $<0.001$ & & & $<0.001$ \\
\hline All free & Ref & & & & & \\
\hline Any free & 1.83 & $1.64-2.04$ & & 1.32 & $1.18-1.49$ & \\
\hline None free & 1.14 & $1.01-1.28$ & & 1.14 & $1.02-1.29$ & \\
\hline Number of hospitalizations in the & revious & ths & $<0.001$ & & & \\
\hline None & Ref & & & & & \\
\hline 1 & 1.15 & $0.99-1.34$ & & & & \\
\hline 2 or more & 1.73 & $1.44-2.08$ & & & & \\
\hline Number of emergency visits in th & previous & nths & $<0.001$ & & & $<0.001$ \\
\hline None & Ref & & & & & \\
\hline 1 & 1.47 & $1.32-1.63$ & & 1.14 & $1.03-1.27$ & \\
\hline 2 or more & 1.84 & $1.63-2.09$ & & 1.32 & $1.18-1.48$ & \\
\hline Self-perceived health and morbiditi & & & & & & \\
\hline Self-perceived health & & & $<0.001$ & & & \\
\hline Very good & Ref & & & & & \\
\hline Good & 1.45 & $0.99-2.12$ & & & & \\
\hline Average & 2.08 & $1.40-3.08$ & & & & \\
\hline Poor & 2.69 & $1.78-4.07$ & & & & \\
\hline Very poor & 2.88 & $1.91-4.32$ & & & & \\
\hline Number of chronic diseases (con & bidities & & $<0.001$ & & & $<0.001$ \\
\hline 1 & Ref & & & & & \\
\hline 2 & 1.59 & $1.41-1.79$ & & 1.28 & $1.10-1.48$ & \\
\hline 3 or more & 2.11 & $1.88-2.31$ & & 1.39 & $1.16-1.66$ & \\
\hline Limitations due to chronic diseas & & & $<0.001$ & & & $<0.001$ \\
\hline No limitations & Ref & & & & & \\
\hline Limitations & 1.80 & $1.64-1.97$ & & 1.34 & $1.21-1.49$ & \\
\hline & & Level & & & & \\
\hline Use of drugs & & & & & & \\
\hline Number of drugs used to treat ch & nic dise & & $<0,001$ & & & $<0,001$ \\
\hline 1 & Ref & & & & & \\
\hline 2 & 1,28 & $1,12-1,46$ & & 1,08 & $0,93-1,26$ & \\
\hline 3 to 4 & 1,89 & $1,67-2,12$ & & 1,43 & $1,21-1,69$ & \\
\hline 5 or more & 2,43 & $2,14-2,76$ & & 1,61 & $1,34-1,94$ & \\
\hline
\end{tabular}

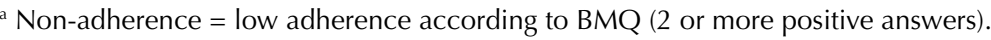

${ }^{\mathrm{b}}$ According to the Brief Medication Questionnaire (BMQ).

${ }^{c}$ Variables grouped by entry in the adjusted analysis model.

${ }^{\mathrm{d}}$ Wald test.

e According to Critério de Classificação Econômica Brasil 2013 - ABEP. Available from: http//www.abep.org. 


\section{DISCUSSION}

Adherence is a multidimensional phenomenon determined by the interaction of a set of factors that affect people's behavior and ability to follow treatment ${ }^{22}$. This study evaluated for the first time the factors associated with low adherence to treatment for chronic diseases in a representative sample of the Brazilian population aged 20 or more, contributing to build evidence on the subject to guide intervention strategies to improve treatment adherence among these patients.

About a third of the adult population showed low adherence to drug treatment for chronic diseases, a result similar to the systematic review that summarized data from international studies on the subject published over 50 years (1948 to 1998) ${ }^{5}$. Previous national studies showed great variability in prevalence, ranging from $17.0 \%$ to $63.5 \%{ }^{6,7,17,18,20}$, but comparing results requires care because of the significant differences between studies in range of samples (local or regional), population subgroups, or focus on specific chronic diseases, such as high blood pressure.

The relationship between socioeconomic factors, such as income and education, and treatment adherence is widely investigated and previous studies have found an association between these variables and adherence, especially in chronic diseases ${ }^{5}$. In this study, low adherence to treatment was higher in individuals with lower levels of educationa, showing that this is a factor that must be considered in health care. Such patients require guidance regarding treatment to better understand the prescribed therapy regimens. On the other hand, economic status was not associated with the treatment of chronic diseases in Brazil.

Regarding demographic factors, the literature suggests that individuals who are young, male, and black show lower adherence to treatment ${ }^{7,9}$. Our findings indicate that, among the Brazilian population, there is no significant difference between men and women, but younger people show lower adherence to treatment.

Residents of the Northeast and Midwest Regions had greater prevalence of low adherence to treatment than other regions, a result previously found by a study that evaluated the prevalence and factors associated with the non-use of continuous drugs among individuals who reported diagnosis of high blood pressure in the Pesquisa Nacional de Domicílios PNAD-2008 ${ }^{6}$ (National Household Sample Survey).

Regarding the characteristics related to the health of individuals, very poor self-perceived health was positively associated with low adherence to treatment in patients treating chronic diseases. A meta-analysis described that patients with better self-perceived health have better adherence to treatment, which can help reduce the worsening of patients, especially those afflicted with chronic diseases ${ }^{4}$.

The demographic transition we are currently experiencing, with an increase in the number of chronic diseases, has led to a growing use of medicines, especially among older adults ${ }^{20}$. In this study, we found a strong association between higher number of chronic diseases and low adherence. The explanation is that the simultaneous treatment of many chronic health conditions can result in polypharmacy, complex regimens in which medicine is taken many times a day, involving drug risks and predisposition to non-adherence ${ }^{10,22}$. Wang et al. (2005) described a significant reduction in the use of antihypertensive drugs in older patients with high blood pressure who have a high prevalence of comorbidities, reinforcing the impact of polypharmacy in adherence to treatment for chronic conditions ${ }^{21}$.

Another factor described as one of the most important related to treatment adherence is medication $\operatorname{costs}^{11,18}$. A meta-analysis showed an $11.0 \%$ higher likelihood of non-adherence to medication in populations with health insurance who had to pay part of their 
medication costs, which may burden the public health system by increasing expenses from hospitalizations because of non-adherence to essential drugs ${ }^{19}$.

In Brazil, patients have free access through the Brazilian Unified Health System (SUS) to a list of essential medicines, with emphasis on the treatment of the most prevalent diseases, such as chronic diseases. However, a study that evaluated the availability of drugs in public health units in the country found low availability of drugs in all population strata ${ }^{12}$. In this study, the highest prevalence of low adherence to treatment was found among individuals who had to pay part of their treatment compared to those who had free access to all medicines needed to treat reported chronic diseases. This finding reinforces the fact that drugs not provided by SUS can lead users to abandon prescribed treatments for not being able to buy them in the private sector with their own resources ${ }^{20}$.

Regarding therapy regimens, the amount of prescribed drugs, the therapy schedule and the side effects are also associated with non-adherence ${ }^{16}$. The complexity of the therapy schedule, where the most relevant element is the number of prescribed drugs, also seems to contribute greatly to adherence to treatment ${ }^{8}$. In this study, individuals who used three or more drugs had a higher prevalence of low adherence to treatment, reinforcing this aspect as an important negative predictor of adherence to treatment.

Among the strategies to improve adherence are patient education, better treatment regimens and better communication between physicians and other health professionals and patients ${ }^{15}$. We noted in this study that individuals who reported seeing more than one doctor to treat their chronic diseases had a higher prevalence of low adherence to treatment, suggesting flaws in the whole care process. A recent systematic review shows that most of the current methods to improve adherence to treatment for chronic health problems are complex and ineffective. This shows the need for progress in this field, including improvement in the design of long-term viable interventions, objective adherence measures, and research capability, which should be sufficient to detect improvements in clinical outcomes of patients ${ }^{14}$.

The study's limitations include the use of self-reporting to measure adherence to drug therapy, which is subject to measurement bias, and the actual cross-sectional design, which does not identify changes in health status, treatment regimens and other factors that can influence the behavior of patients' adherence to treatment over time $e^{4}$. Moreover, the great variability of methods, tools and recall periods used to measure adherence limits the comparability of results. Despite the limitations, we were able to estimate in an unprecedented manner the factors associated with low adherence to drug therapy for chronic diseases in Brazil, contributing to the production of evidence to support the guidance of interventions addressing the subject in the country.

The results indicate that low adherence to drug treatment for chronic diseases in Brazil is relevant, and that regional and demographic differences and those related to patients' health care and therapy regimen require coordinated action between health professionals, researchers, managers and policy makers.

\section{REFERENCES}

1. Alleyne G, Binagwaho A, Haines A, Jahan S, Nugent R, Rojhani A et al. Embedding non-communicable diseases in the post-2015 development agenda. Lancet. 2013;381(9866):566-74. DOI:10.1016/S0140-6736(12)61806-6

2. Ben AJ, Neumann CR, Mengue SS. Teste de Morisky-Green e Brief medication Questionnaire para avaliar adesão a medicamentos. Rev Saude Publica. 2012;46(2):279-89. DOI:10.1590/S0034-89102012005000013 
3. Coleman $\mathrm{Cl}$, Limone B, Sobieraj DM, Lee $\mathrm{S}$, Roberts MS, Kaur R et al. Dosing frequency and medication adherence in chronic disease. J Manag Care Pharm. 2012;18(7):527-39. DOI:10.18553/jmcp.2012.18.7.527

4. DiMatteo MR, Giordani PJ, Lepper HS, Croghan TW. Patient adherence and medical treatment outcomes: a meta-analysis. Med Care. 2002 Sep;40(9):794-811. DOI:10.1097/00005650-200209000-00009

5. DiMatteo MR. Variations in patients' adherence to medical recommendations: a quantitative review of 50 years of research. Med Care. 2004;42(3):200-9. DOI:10.1097/01.mlr.0000114908.90348.f9

6. Ferreira RA, Barreto SM, Glatti L. Hipertensão arterial referida e utilização de medicamentos de uso contínuo no Brasil: um estudo de base populacional. Cad Saude Publica. 2014;30(4):815-26. DOI:10.1590/0102-311X00160512

7. Girotto E, Andrade SM, Cabrera MA, Matsuo T. Adesão ao tratamento farmacológico e não farmacológico e fatores associados na atenção primária da hipertensão arterial. Ciênc Saude Coletiva. 2013;18(6):1763-72. DOI:10.1590/S1413-81232013001400027

8. Iskedjian M, Einarson TR, MacKeigan LD, Shear N, Addis A, Mittmann N et al. Relationship between daily dose frequency and adherence to antihypertensive pharmacotherapy: evidence from a meta-analysis. Clin Therap. 2002;24(2):302-16. DOI:10.1016/S0149-2918(02)85026-3

9. Krousel-Wood M, Islam T, Webber LS, Re RN, Morisky DE, Muntner P. New medication adherence scale versus pharmacy fill rates in seniors with hypertension. Am J Manag Care. 2009;15(1):59-66.

10. Mengue SS, Bertoldi AD, Boing AC, NUL Tavares, da Silva Dal Pizzol T, Oliveira MA, et al. Pesquisa Nacional sobre Acesso, Utilização e Promoção do Uso Racional de Medicamentos (PNAUM): métodos do inquérito domiciliar. Rev Saude Publica. 2016;50(supl 2):4s. DOI:10.1590/S1518-8787.2016050006156

11. Maciejewski ML, Bryson CL, Perkins M, Blough DK, Cunningham FE, Fortney JC et al. Increasing copayments and adherence to diabetes, hypertension, and hyperlipidemic medications. Am J Manag Care. 2010;16(1):e20-34.

12. Mendes LV, Campos MR, Chaves GC, Silva RM, Freitas PS, Costa KS et al. Disponibilidade de medicamentos nas unidades básicas de saúde e fatores relacionados: uma abordagem transversal. Saude Debate. 2014;38 nº spe:109-23. DOI:10.5935/0103-1104.2014S009

13. Mengue SS, Bertoldi AD, Boing AC, NUL Tavares, da Silva Dal Pizzol T, Oliveira MA, et al. Pesquisa Nacional sobre Acesso, Utilização e Promoção do Uso Racional de Medicamentos (PNAUM): métodos do inquérito domiciliar. Rev Saude Publica. 2016;50(supl 2):4s. DOI:10.1590/S1518-8787.2016050006156

14. Nieuwlaat R, Wilczynski N, Navarro T, Hobson N, Jeffery R, Keepanasseril A et al. Interventions for enhancing medication adherence. Cochrane Database Syst Rev. 2014;(11):CD000011. DOI:10.1002/14651858.CD000011.pub4

15. Osterberg L, Blaschke T. Adherence to medication. New Engl J Med. 2005;353(5):487-97. DOI:10.1056/NEJMra050100

16. Prado JC Jr, Kupek E, Mion D Jr. Validity of four indirect methods to measure adherence in primary care hypertensives. J Hum Hypertens. 2007;21(7):579-84. DOI:10.1038/sj.jhh.1002196

17. Remondi FA, Cabrera MAS, Souza RKT. Não adesão ao tratamento medicamentoso contínuo: prevalência e determinantes em adultos de 40 anos e mais. Cad Saude Publica. 2014;30(1):126-36. DOI:10.1590/0102-311X00092613

18. Santa-Helena ETD, Nemes MIB, Eluf Neto J. Fatores associados à não-adesão ao tratamento com anti-hipertensivos em pessoas atendidas em unidades de saúde da família. Cad Saude Publica. 2010;26(12):2389-98. DOI:10.1590/S0102-311X2010001200017

19. Sinnott SJ, Buckley C, O'Riordan D, Bradley C, Whelton H. The effect of copayments for prescriptions on adherence to prescription medicines in publicly insured populations; a systematic review and meta-analysis. PLoS One. 2013;8(5):e64914. DOI:10.1371/journal.pone.0064914

20. Tavares NUL, Bertoldi AD, Thumé E, Facchini LA, França GVA, Mengue SS. Fatores associados à baixa adesão ao tratamento medicamentoso em idosos. Rev Saude Publica. 2013;47(6):1-9. DOI:10.1590/S0034-8910.2013047004834 
21. Wang PS, Avorn J, Brookhart MA, Mogun H, Schneeweiss S, Fischer MA et al. Effects of noncardiovascular comorbidities on antihypertensive use in elderly hypertensives. Hypertension. 2005;46(2):273-9. DOI:10.1161/01.HYP.0000172753.96583.e1

22. World Health Organization. Adherence to long-term therapies: evidence for action. Geneva: World Health Organization; 2003.

Funding: Department of Pharmaceutical Services and Strategic Health Supplies (DAF) and Department of Science and Technology (DECIT) of the Secretariat of Science, Technology and Strategic Inputs of the Ministry of Health (SCTIE/MS - Process 25000.111834/2011-31).

Authors' Contributions: design, analysis and interpretation of results and critical review of intellectual content: NULT, ADB, SSM, TSD. All authors participated in drafting the study, approved the final version of the manuscript and declare they are responsible for all aspects of the work, ensuring its accuracy and integrity.

Acknowledgments: Departments of Science and Technology (DECIT) and Pharmaceutical and Strategic Health Supplies (DAF) of the Secretariat of Science, Technology and Strategic Inputs (SCTIE) of the Ministry of Health (MS) for financial and technical support to carry out the National Survey on Access, Use and Promotion of Rational Use of Medicines, and in particular the team that worked on data collection, represented here by Professor Alexandra Crispim Boing and the project's statistical support team, by Amanda Ramalho Silva, Andréia Turmina Fontanella and Luciano Santos Pinto Guimarães and Giovanny Araújo França.

Conflict of Interest: The authors declare no conflict of interest. 